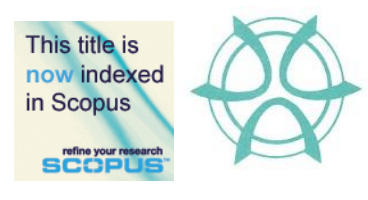

PLANNING MALAYSIA:

Journal of the Malaysian Institute of Planners

Volume XI (2013), Page 85 - 96

\title{
USER'S PREFERENCE AND PERCEPTION ON THE PEDESTRIAN CROSSING IN MALAYSIA: THE CASE OF AMPANG ROAD, KUALA LUMPUR
}

\author{
Oliver Ling Hoon Leh ${ }^{1}$, Zamila Zamri ${ }^{2}$, Mohd Zamreen Mohd Amin ${ }^{3} \&$ \\ Marlyana Azyyati Marzukhi ${ }^{4}$ \\ 1,2,3\&4 Faculty of Architecture, Planning \& Surveying, \\ UNIVERSITI TEKNOLOGI MARA SHAH ALAM
}

\begin{abstract}
The issue of road accident among pedestrian is highly emotional and raising a very strong interest within the public, and the media, mainly due to the victims are often children and elderly people. However, most of the pedestrians are lack in interest of using the pedestrian crossing. Thus, a study on the perception and preference of the pedestrian on the pedestrian crossing was being carried out in Ampang Road, Kuala Lumpur as a case study. The objectives of the study are to analyze pedestrians' preference and perception on the various types of pedestrian crossing and to conclude findings and construct strategic recommendation based on the findings. The study has been carried out on three (3) types of pedestrian crossing in Ampang Road which are overhead crossing, underpass crossing and signalised crossing. This study involved with questionnaire survey on the total of 92 respondents, and on-site observation by researcher. Statistical analysis has been carried out, i.e. the frequency, mean and percentage. There are three (3) major findings in this study. The most chosen type of pedestrian crossing is the overhead crossing. However, the underpass crossing was given the best score in term of the quality of the pedestrian crossing (based on the respondents' perception). Meanwhile, the signalised crossing is the most preferable type of crossing. The reasons and the explanation were discussed in the paper. The study is concluded with strategic recommendation for pedestrian crossing planning.
\end{abstract}

Keywords: Overhead crossing; Perception study; Signalised crossing; Underpass crossing.

\footnotetext{
${ }^{1}$ Senior lecturer at the Centre of Studies for Town \& Regional Planning, Universiti Teknologi Mara. Email: oliver3979@salam.uitm.edu.my
} 
Oliver Ling Hoon Leh, Zamila Zamri, Mohd Zamreen Mohd Amin \& Marlyana Azyyati Marzukhi

User's Preference and Perception on the Pedestrian Crossing in Malaysia: The Case of Ampang Road, Kuala Lumpur

\section{INTRODUCTION}

Pedestrian crossings are the critical points in the traffic network that enable pedestrians to cross a road safely. At such intersections, motorists, cyclists, and pedestrians often have to deal with complex situations and be aware of the position, movement, and intent of other users. Mixed traffic of vehicles and pedestrians are common in urban intersections. The safety of the pedestrian depends on the type, design and location of pedestrian crossing, as well as the attitude of the road users. Abdul Aziz Chik et al. (2000) found that violation of the red signal aspect by both the motorists and pedestrians is close to $70 \%$ at midblock signalised pedestrian crossings in Malaysia. It shows the possible negative attitude of road users. Besides, from the general observation, we can also notice that there are pedestrians who always choose to cross a road without using a designated pedestrian crossing. Pedestrian tends to cross a road when it suits them, in terms of convenience and time saving rather than consideration on the potential safety implications (Martin, 2006).

Besides the factor of pedestrian attitude, the quality of the crossing facility might also affect the choice of pedestrian. Condition of crossing area is the main factor which influences people in using a crossing. Low quality of pedestrian crossing includes badly installed drop kerbs, barrier of movement, unsuitable height of crossing, and others have made people feel inconvenience to use it, then the crossing will not give benefit to a person who lives in the area (Martin, 2006). Thus, the preference and perception of pedestrian on the pedestrian crossings are necessary to be examined. Good, user friendly and preferable pedestrian walkways are always treated as an important element in improving the quality of an area including a neighbourhood area (Norainah et al., 2012).

\section{LITERATURE REVIEW}

A pedestrian crossing is a designated point on a road to assist pedestrians wishing to cross. The crossing is designed to keep pedestrians in a group where motorists can see them, and they can cross a road safely. According to Nik Ibtishamiah Ibrahim et al. (2005), provisions of adequate and safe pedestrian facilities in the urban setting would encourage more people to walk, thus increasing the pedestrian traffic. The demand for the improvement of pedestrian facilities is raised due to the reasons such as difficulties in crossing heavily trafficked intersections, conflicts between pedestrians and cyclists, physical 
barriers, low visibility, improper design of handicapped accessible ramps and so on (Thambiah Muraleetharan, 2005).

Pedestrian perceptions about various crossing options show that it does influence their decisions when they are presented with these different options along their route. Marked crosswalks at signalized intersections are seen by some as unsafe because of vehicles might fail to follow the signal. Some pedestrians favor midblock crosswalks because they are more convenient and eliminate the threat posed by left turning vehicles, but others perceive them as unsafe because they feel motorists will only be looking for crossing pedestrians at intersections (Akin, 2007).

There are several factors that influence the preference of pedestrian to use a crossing, which includes the general condition of an area, generality of the crossing, and condition of the crossing area (Martin, 2006). Busy road and busy town will make people choose to use the public transport, thus increases the usage of pedestrian crossings. However, the low quality or unsafe crossings will discourage people to use it. In general, there are several key psychological principles that attract pedestrian to a place, which are security, comfort, convenience, efficiency and affordability, and welcoming feeling (Fitzpatrick et al., 2006).

Besides the physical condition of pedestrian crossing, other major factors that affect the preference of pedestrian are their attitude and the effectiveness of enforcement. Pedestrians are always linked to the impatience to respect the signals, and use overpasses or underpasses. When the safety aspects and other related attributes were appraised, pedestrians did not favor any type of crossing in particular (Akin, 2007).

\section{OBJECTIVES, CASE STUDY AND METHODS}

A study on the perception and preference of the pedestrian on the pedestrian crossing was carried out in Ampang Road, Kuala Lumpur as the case study. The objectives of the study are (i) to analyze pedestrians' preference and perception on the various types of pedestrian crossing and (ii) to conclude findings and construct strategic recommendation.

The study has been carried out on three (3) types of pedestrian crossing in Ampang Road (Figure 1) which are overhead crossing (crossing A, namely Ampang, Figure 2), underpass crossing (crossing B, namely Ampang Park, Figure 3) and signalised crossing (crossing C, namely KLCC, Figure 4). All the 
Oliver Ling Hoon Leh, Zamila Zamri, Mohd Zamreen Mohd Amin \& Marlyana Azyyati Marzukhi

User's Preference and Perception on the Pedestrian Crossing in Malaysia: The Case of Ampang Road, Kuala Lumpur

three (3) pedestrian crossings are located along the Ampang Road, and within the administration of Kuala Lumpur City Hall.

This study was carried out using the questionnaire survey on the total number of 92 respondents, and on-site observation by researcher. The size of the respondent is calculated based on the total number of users of 1,233 (column $\mathrm{B}$, Table 1) with the level of error of $10 \%$. Table 1 shows the distribution of the respondents.

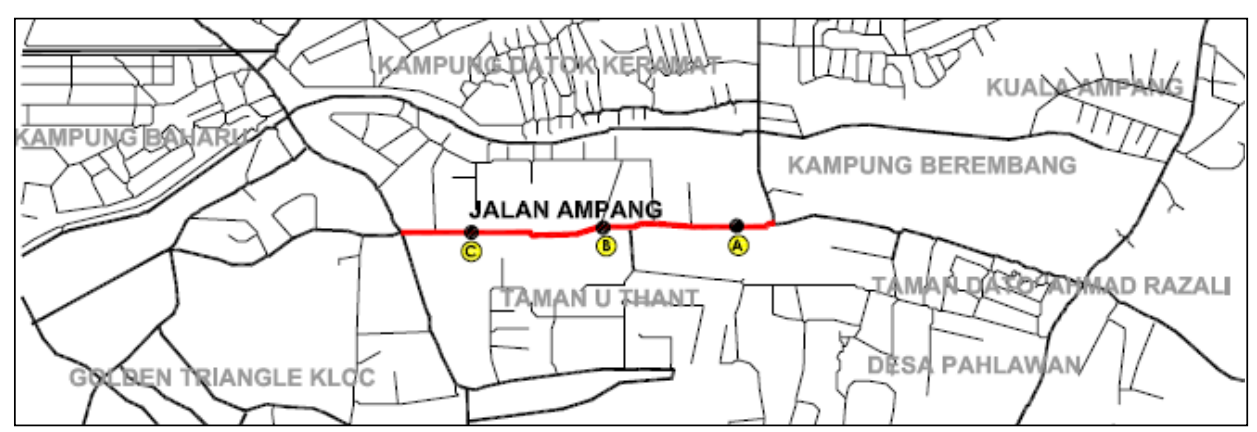

Figure 1: Location of the three (3) pedestrian crossings

Source of base map: Jabatan Kerja Raya Wilayah Persekutuan Kuala Lumpur (2013)

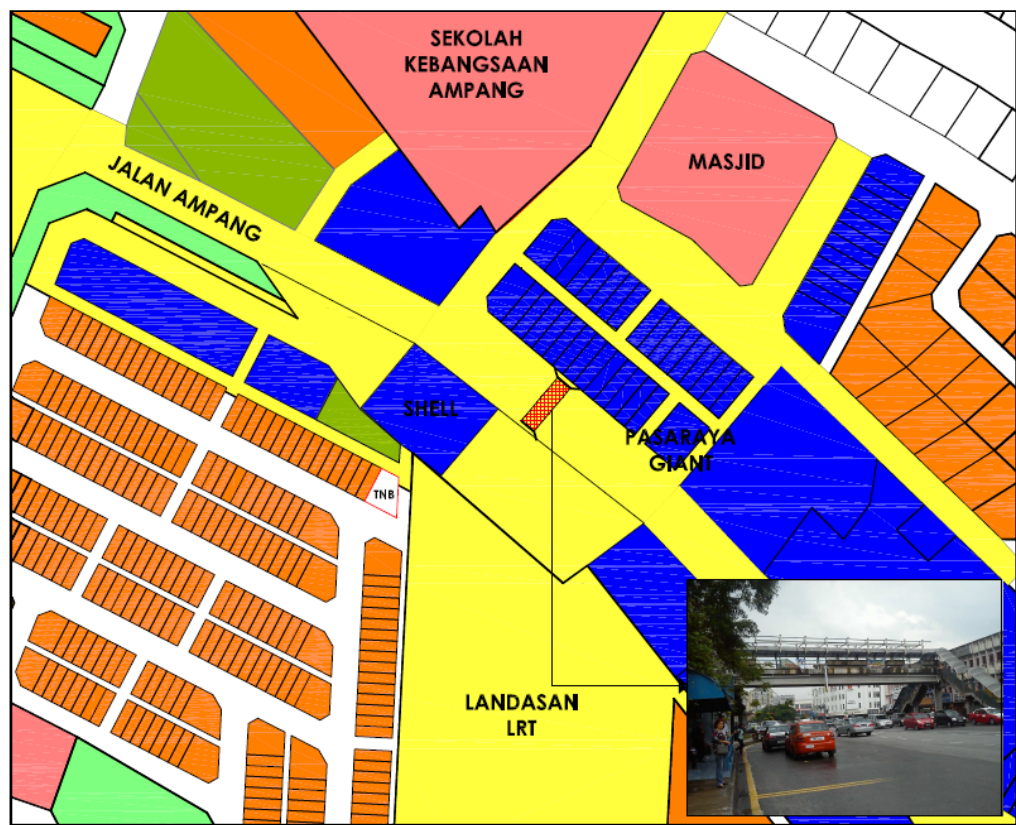

Figure 2: Location of the pedestrian crossing A (Ampang)

Source of base map: Jabatan Perancangan Bandar \& Desa Semenanjung Malaysia (2013) 
PLANNING MALAYSIA:

Journal of the Malaysia Institute of Planners (2013)

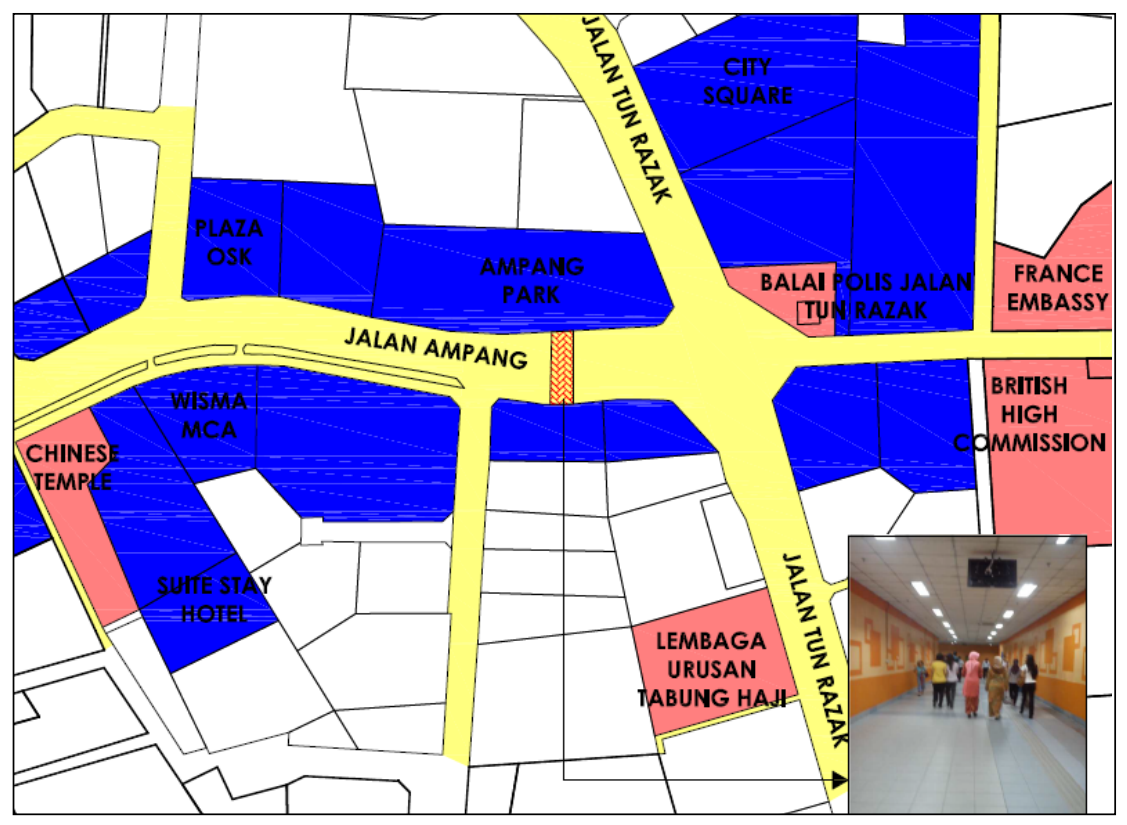

Figure 3: Location of the pedestrian crossing B (Ampang Park)

Source of base map: Jabatan Perancangan Bandar \& Desa Semenanjung Malaysia (2013)

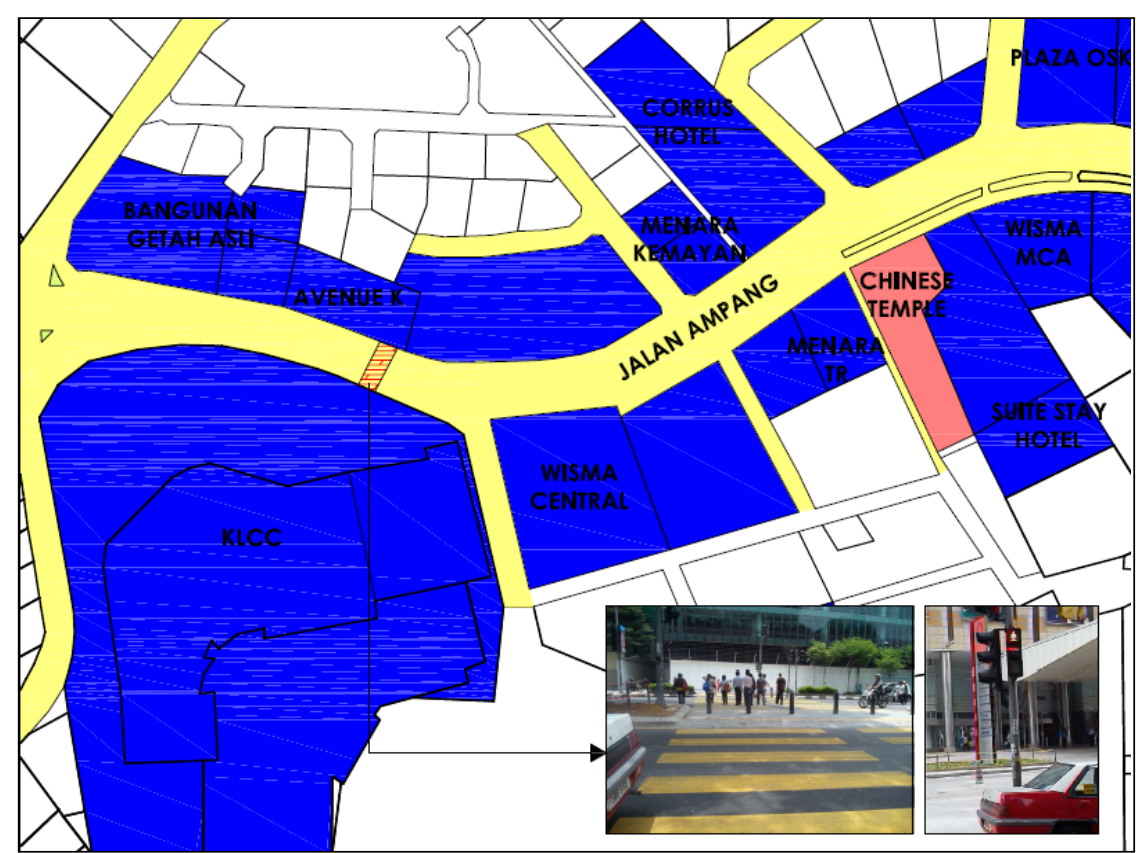

Figure 4: Location of the pedestrian crossing C (KLCC) 
Oliver Ling Hoon Leh, Zamila Zamri, Mohd Zamreen Mohd Amin \& Marlyana Azyyati Marzukhi

User's Preference and Perception on the Pedestrian Crossing in Malaysia: The Case of Ampang Road, Kuala Lumpur

Source of base map: Jabatan Perancangan Bandar \& Desa Semenanjung Malaysia (2013)

Table 1: Distribution of respondents

\begin{tabular}{|l|l|l|l|l|}
\hline & $\begin{array}{l}\text { A } \\
\text { Total } \\
\text { number } \\
\text { users }\end{array}$ & $\begin{array}{l}\text { B } \\
\text { Average } \\
\text { number } \\
\text { users }\end{array}$ & $\begin{array}{l}\text { C } \\
\text { Percentage } \\
(\%)\end{array}$ & $\begin{array}{l}\text { Size of } \\
\text { respondents } \\
\text { (sample) }\end{array}$ \\
\hline $\begin{array}{l}\text { Crossing A - } \\
\text { Ampang }\end{array}$ & 1,248 & 416 & 33.7 & 31 \\
\hline $\begin{array}{l}\text { Crossing B - } \\
\text { Ampang Park }\end{array}$ & 867 & 289 & 23.4 & 22 \\
\hline $\begin{array}{l}\text { Crossing C - } \\
\text { KLCC }\end{array}$ & 1,586 & 528 & 42.9 & 39 \\
\hline Total & $\mathbf{3 , 7 0 1}$ & $\mathbf{1 , 2 3 3}$ & $\mathbf{1 0 0 . 0}$ & $\mathbf{9 2}$ \\
\hline
\end{tabular}

Notes:

1. Column A: The total number of users for 3 periods of time (7-8 am; $1-2 \mathrm{pm} ; 6-7 \mathrm{pm})$

2. Column B: Average number of users per hour.

3. Respondents were distributed based on the percentage of actual size of users for the 3 crossings.

\section{FINDINGS AND DISCUSSION}

\section{Use of Pedestrian Crossing}

Table 2 shows the most chosen pedestrian crossing in the Ampang Road, Kuala Lumpur by respondents. It shows that the highest percentage $(40.2 \%)$ of respondents mostly use the crossing A (overhead crossing - Ampang), followed by the crossing $\mathrm{C}$ (signalised crossing - KLCC) with $32.6 \%$. For the crossing $\mathrm{B}$ (underpasses crossing - Ampang Park), there is only $25 \%$ of the respondents choose that particular point for the road crossing purpose.

As a reference to the Table 1 (column A), during the survey, the crossing C (KLCC) was identified with the largest number of user. However, according to the respondents, the crossing A (Ampang) is the most used (or chosen) pedestrian crossing. It is due to the reason of the majority of the users are living in Ampang area (Taman Kosas, Bukit Indah, Bandar Baru Ampang, etc.) who uses the crossing A (overhead) for the purpose of working trip. The crossing A is located near to LRT station and bus stop. It is the only crossing (among the three crossings) which located between a residential area and commercial area. Meanwhile, crossing B and C are connecting a commercial area with another commercial area as well as a Light Rail Transit (LRT) station, but, not the residential area. 
Table 2: The most chosen pedestrian crossing by respondents

\begin{tabular}{|l|l|}
\hline \multicolumn{1}{|l|}{} & $\mathbf{\%}$ \\
\hline Crossing A (Overhead - Ampang) & 40.2 \\
\hline Crossing C (Signalised - KLCC) & 32.6 \\
\hline Crossing B (Underpass - Ampang Park) & 25.0 \\
\hline No specific crossing & 2.2 \\
\hline Total & $\mathbf{1 0 0 . 0}$ \\
\hline
\end{tabular}

\section{Preference on the Pedestrian Crossing}

Table 3 shows that out of the 92 respondents, 47 respondents $(51.1 \%)$ choose the signalised crossing as the most preferable type of crossing. The second preferable type of crossing is underpass (crossing B) with $32.6 \%$ of respondents. The rest of the respondents (16.3\%) prefer the overhead crossing (crossing A). It shows that most of the respondents (pedestrians) prefer to use at-grade (signalised) pedestrian crossing as compared to the overhead and underpass. It might due to the convenience of the signalised crossing without requiring pedestrian to use the staircase. Besides, the signalised crossing is less time consuming as compared to the overhead and underpass.

In the other hand, it is found that the majority of the respondents do not prefer the overhead crossing (crossing A) even though they use it the most. If there is a choice, most of them prefer to use signalised crossing or underpass. This result might not be suitable for other area where the quality of the underpass is dark, dirty or not well maintained. The quality of the underpass especially the safety aspect in the study area (Ampang Park) is contributing to a higher preferable rate as compared to the overhead bridge.

Table 3: The most preferable type of pedestrian crossing by respondents

\begin{tabular}{|l|l|}
\hline \multicolumn{2}{|l|}{ \%rossing C (Signalised - KLCC) } \\
\hline Crossing B (Underpass - Ampang Park) & 51.1 \\
\hline Crossing A (Overhead - Ampang) & 32.6 \\
\hline Total & 16.3 \\
\hline
\end{tabular}

\section{Perception on the Pedestrian Crossing}

Respondents were given the opportunity to evaluate the pedestrian crossings provided at the study area. There are 8-9 items have been selected for the evaluation on their perception on the pedestrian crossings. The respondents' perceptions have been scaled by: $1=$ strongly agreed (SA, refer to the highest 
Oliver Ling Hoon Leh, Zamila Zamri, Mohd Zamreen Mohd Amin \& Marlyana Azyyati Marzukhi

User's Preference and Perception on the Pedestrian Crossing in Malaysia: The Case of Ampang Road, Kuala Lumpur

level of quality), $2=$ agreed (A), $3=$ disagreed (D) and $4=$ strongly disagreed (SD, refer to lowest quality level). The mean of each item is used in the discussion to show the perception of respondents on the quality of every pedestrian crossing. The evaluation covers the aspects of location, visibility, lighting, facility, connectivity, safety, condition, and design of pedestrian crossing.

For the crossing A (overhead - Ampang), the best items are on the location of the crossing $($ mean $=1.76)$ and the connectivity $($ mean $=1.86)$. However, the lighting is not really adequate with a mean value of 2.55 , and facilities for visually impaired and disabled users are not adequate $($ mean $=$ 3.33) (Table 4). This result can be used to explain the high usage (Table 2 and 3 ) of crossing A (due to the good location and connectivity), but less preferable by users (due to inadequate of lighting and facilities).

Table 4: Perception of pedestrian on Crossing A

\begin{tabular}{|c|c|c|c|c|c|}
\hline Item & 1 (SA) & $2(\mathrm{~A})$ & 3 (D) & 4 (SD) & Mean \\
\hline Strategic location of the crossing & $23.9 \%$ & $76.1 \%$ & - & - & 1.76 \\
\hline $\begin{array}{l}\text { Well connected with bus } \\
\text { service/LRT }\end{array}$ & $23.9 \%$ & $76.1 \%$ & - & - & 1.76 \\
\hline $\begin{array}{l}\text { Ramps \& pavement in good } \\
\text { condition }\end{array}$ & - & $66.3 \%$ & $27.2 \%$ & $6.5 \%$ & 2.40 \\
\hline Visibility of traffic signs & $3.3 \%$ & $69.6 \%$ & $26.1 \%$ & $1.1 \%$ & 2.25 \\
\hline Lighting is adequate & $1.1 \%$ & $44.6 \%$ & $52.2 \%$ & $2.2 \%$ & 2.55 \\
\hline $\begin{array}{l}\text { Height \& gradient of the staircase } \\
\text { is suitable }\end{array}$ & $2.2 \%$ & $72.8 \%$ & $23.9 \%$ & $1.1 \%$ & 2.24 \\
\hline $\begin{array}{l}\text { Adequate facility for visually } \\
\text { impaired \& disabled users }\end{array}$ & - & $7.6 \%$ & $52.2 \%$ & $40.2 \%$ & 3.33 \\
\hline Feel save & $15.2 \%$ & $53.3 \%$ & $31.5 \%$ & - & 2.16 \\
\hline $\begin{array}{l}\text { Linked between intersections, } \\
\text { buildings \& others (parking, bus } \\
\text { stop, LRT station) }\end{array}$ & $14.5 \%$ & $85.9 \%$ & - & - & 1.86 \\
\hline TOTAL & & & & & 2.63 \\
\hline
\end{tabular}

For the crossing B (underpass - Ampang Park, Table 5), all the items are evaluated with mean values less than 2.0 based on the perceptions of the respondents. That means respondents are satisfied with the quality of the crossing B especially on the condition, lighting and facilities. This result can be related to the previous analysis on preference of respondents on the type of crossing, whereby, the underpass is the second preferable type of pedestrian crossing after the signalised crossing (Table 3). Even though, the respondents have the best perception on underpass (crossing B) as compared to crossing A 
(Table 4) and crossing $\mathrm{C}$ (Table 6), most of the respondents still choose the signalised crossing $(\mathrm{C})$ as the most preferable type of crossing (Table 3 ).

Table 5: Perception of pedestrian on Crossing B

\begin{tabular}{|c|c|c|c|c|c|}
\hline Item & 1 (SA) & $2(\mathbf{A})$ & 3 (D) & 4 (SD) & Mean \\
\hline Strategic location of the crossing & $21.7 \%$ & $77.2 \%$ & $1.1 \%$ & - & 1.79 \\
\hline $\begin{array}{l}\text { Well connected with bus } \\
\text { service/LRT }\end{array}$ & $21.7 \%$ & $78.3 \%$ & - & - & 1.78 \\
\hline $\begin{array}{l}\text { Ramps \& pavement in good } \\
\text { condition }\end{array}$ & $46.7 \%$ & $52.2 \%$ & $1.1 \%$ & - & 1.54 \\
\hline Visibility of traffic signs & $40.2 \%$ & $57.6 \%$ & $2.2 \%$ & - & 1.62 \\
\hline Lighting is adequate & $46.7 \%$ & $53.3 \%$ & - & - & 1.53 \\
\hline $\begin{array}{l}\text { Adequate facility for visually } \\
\text { impaired \& disabled users }\end{array}$ & $48.9 \%$ & $50.0 \%$ & $1.1 \%$ & - & 1.52 \\
\hline Feel safe & $42.4 \%$ & $56.5 \%$ & $1.1 \%$ & - & 1.59 \\
\hline $\begin{array}{l}\text { Linked between intersections, } \\
\text { buildings \& others (parking, bus } \\
\text { stop, LRT station) }\end{array}$ & $38.0 \%$ & $62.0 \%$ & - & - & 1.61 \\
\hline TOTAL & & & & & 1.55 \\
\hline
\end{tabular}

According to the perception of the respondents, crossing $\mathrm{C}$ (signalised KLCC, Table 6) can be considered as moderate (overall mean value of 1.90), which is better than crossing A (overhead, overall mean value of 2.63, Table 4) but less satisfied than crossing B (underpass, overall mean value of 1.55, Table 5). For the crossing $C$, all the items show mean values of less than 2.0 except the items of "facilities for visually impaired and disabled", and "adequate time for crossing (with green light)" which show mean values of 2.18 and 2.13 respectively. Crossing $\mathrm{C}$ with the mean values of close to 2.0 or fewer (Table 6) is the most preferable type of pedestrian crossing by respondents (Table 3 ).

Table 6: Perception of pedestrian on Crossing C

\begin{tabular}{|l|l|l|l|l|l|}
\hline Item (SA) & $\mathbf{2}(\mathbf{A})$ & $\mathbf{3}$ (D) & $\mathbf{4}$ (SD) & Mean \\
\hline Strategic location of the crossing & $46.7 \%$ & $53.3 \%$ & - & - & 1.53 \\
\hline $\begin{array}{l}\text { Well connected with bus } \\
\text { service/LRT }\end{array}$ & $46.7 \%$ & $53.3 \%$ & - & - & 1.53 \\
\hline $\begin{array}{l}\text { Kerb \& crossing ramps in good } \\
\text { condition }\end{array}$ & $28.3 \%$ & $69.6 \%$ & $2.2 \%$ & - & 1.67 \\
\hline Visibility of traffic signs & $16.3 \%$ & $78.3 \%$ & $5.4 \%$ & - & 1.89 \\
\hline Functioning of traffic light & $17.4 \%$ & $78.3 \%$ & $4.3 \%$ & - & 1.87 \\
\hline $\begin{array}{l}\text { Adequate facility for visually } \\
\text { impaired \& disabled users }\end{array}$ & $4.3 \%$ & $72.8 \%$ & $22.8 \%$ & - & 2.18 \\
\hline $\begin{array}{l}\text { Adequate time for crossing (with } \\
\text { green light) }\end{array}$ & $6.5 \%$ & $73.9 \%$ & $19.6 \%$ & - & 2.13 \\
\hline
\end{tabular}


Oliver Ling Hoon Leh, Zamila Zamri, Mohd Zamreen Mohd Amin \& Marlyana Azyyati Marzukhi

User's Preference and Perception on the Pedestrian Crossing in Malaysia: The Case of Ampang Road, Kuala Lumpur

\begin{tabular}{|l|l|l|l|l|l|l|}
\hline $\begin{array}{l}\text { Linked between intersections, } \\
\text { buildings \& others (parking, bus } \\
\text { stop, LRT station) }\end{array}$ & $21.7 \%$ & $78.3 \%$ & - & - & 1.78 \\
\hline $\begin{array}{l}\text { Pedestrian always follows the } \\
\text { signal }\end{array}$ & $21.7 \%$ & $76.1 \%$ & $2.2 \%$ & - & 1.80 \\
\hline TOTAL Note: $1=$ Strongly Agreed (SA); 2= Agreed (A); 3= Disagreed (D); 4= Strongly Disagreed (SD)
\end{tabular}

\section{CONCLUSION AND RECOMMENDATION}

To conclude based on the perception of most of the respondents, the quality of crossing B (underpass at the KLCC) is the best as compared to the crossing A and C. However, most of the respondents are still prefer to use signalised (atgrade) crossing due to the convenience factor. Thus, the effort of improving the quality of facilities alone is not being able to change the public preference on the type of crossing. Most of people still prefer to use the at-grade crossing which is more convenience with less time consuming, and it is suitable for all including the disabled people.

Overhead and underpass crossings require users to climb up and down the staircase. It is discouraging people to use it. Thus, in order to encourage people to use the pedestrian crossing, more signalised pedestrian crossings should be provided instead of overhead and underpass crossings. However, the issue is whether shall we allow more intersections of pedestrian walkway and automobile carriageway (critical points) or avoid it by providing more underpass or overhead crossings, which is not preferred by the majority of pedestrians.

With the purpose of encouraging people to walk and use the pedestrian crossing, and reducing the car dependency, well-designed at-grade signalised pedestrian crossings should be provided. However, it should be applied together with other urban design principles for the convenience of pedestrians. Urban design concept such as Transit Oriented Development (TOD) or walkable design can be studied in future. Previous study in Petaling Jaya and Kuala Lumpur showed that TOD principles/features are able to encourage people to ride on public transport, to walk, and at the same time use less of their private vehicles (Ling, et al., 2010). 


\section{REFERENCES}

Abdul Aziz Chik et al. (2000). Midblock Signalled Pedestrian Crossing Alternative Controller Algorithm. Journal of the Civil Engineering 12 (1).

Akin, D. (2007). Pedestrian Crossing Compliance Characteristics At-Grade Signalized Crosswalks: Case Study in a Downtown University Campus Environment. Transportation Research Board $86^{\text {th }}$ Annual Meeting. Washington, D.C.

Fitzpatrick, K., et al. (2006). Improving Pedestrian Safety at Unsignalized Crossings. Transportation Research Board. Washington, DC: Transit Cooperative Research Program.

Jabatan Kerja Raya Wilayah Persekutuan Kuala Lumpur (2013). Road Circulation Map.

Jabatan Perancangan Bandar \& Desa Semenanjung Malaysia (2013). Map of Kuala Lumpur.

Ling, OHL, Ting, KH, Dasimah Omar, Jamalunlaili Abdullah, Tee, SF. (2010). Transit Oriented Neighbourhod for Better Environmental Health. 2010 International Conference on Science \& Social Research (CSSR 2010), 5-7 Dec. 2010, Kuala Lumpur.

Martin, A. (2006). Factors Influencing Pedestrian Safety: A Literature Review. Project Report PPR241. Final Version. TRL Limited.

Nik Ibtishamiah Ibrahim et al. (2005). Motorists and Pedestrian Interaction at Unsignalised Pedestrian Crossing. Journal of the Eastern Asia Society for Transportation Studies 5: 120-125.

Norainah A. R., Dasimah O. \& Abdul Ghani S. (2012). Determinant Factors of Neighbourhood Quality. Planning Malaysia 10: 1-16.

Thambiah Muraleetharan (2005). Method to Determine Pedestrian Level-ofService for Crosswalks at Urban Intersections. Journal of the Eastern Asia Society for Transportation Studies 6. 
Oliver Ling Hoon Leh, Zamila Zamri, Mohd Zamreen Mohd Amin \& Marlyana Azyyati Marzukhi

User's Preference and Perception on the Pedestrian Crossing in Malaysia: The Case of Ampang Road, Kuala Lumpur 